Thorax (1946), 1, 48-70.

\title{
SPONTANEOUS PERFORATION OF THE OESOPHAGUS \\ REVIEW OF THE LITERATURE AND REPORT OF THREE NEW CASES \\ BY
}

\author{
N. R. BARRETT \\ From the Thoracic Surgical Unit at Horton War Hospital \\ "It is probable that if a man knew all about his subject he would \\ have no desire to write about it."-A. S. Neill, 1925
}

\section{Historical Notes}

In the year 1723 Hermann Boerhaave was called to the bedside of the Grand Admiral of Holland. who died in such unusual circumstances that he obtained permission to make a post-mortem examination. The results of this inquiry were published in the following year in a pamphlet entitled "Atrocis, nec descripti prius, Morbi Historia."1

\section{Abstract by Mackenzie of the Case of Rupture of the Oesophagus OBSERVED BY BOERHAAVE}

(The original occupies seventy closely printed pages)

The subject of this accident was Baron de Wassenaer, a man over fifty years of age, and of powerful frame, whose appearance betokened perfect health. In his youth he had frequently suffered from "angina," and for many years during the winter he had been subject to gout, attributed by himself to overeating and want of exercise. After a full meal he always felt a sensation of great weight at the pit of the stomach, and to relieve this he was in the habit of taking ipecacuanha in a copious infusion of blessed-thistle (carcuus or cnicus benedictus. This her $b$ was once much used as a febrifuge and tonic, and as a mild diaphoretic. The infusion is said to induce vomiting or rather to assist the action of emetics, but probably it has much the same effect as warm water), though he sometimes used the latter beverage alone.

At the time of the accident which caused his death, Baron de Wassenaer was atoning by low diet for an excess at table committed three days before, and a glance at his last meal-an early dinner-may give some idea of the character and amount of his food when he was not stinting his appetite. It has long been supposed that the Baron was a gross feeder, but after a careful perusal of the case, so eminent an authority as Prof. von Ziemssen does not think this opinion warranted by the facts. An examination of the following list, which does not represent the bill of fare, but only that portion of it which was 
partaken of by the Baron, will enable the reader to determine for himself a matter which has an important aetiological bearing on the case:

\author{
Dinner : \\ Veal Soup, with Herbs \\ Boiled Lamb and Cabbage \\ Fried Sweetbread and Spinach \\ Duck \\ Two Larks \\ Compote of Apples \\ Dessert \\ Pears, Grapes, Sweetmeats \\ Beer and Moselle
}

In justice to Baron de Wassenaer it must be stated that he does not seem to have eaten largely of any of these viands, except perhaps of the duck, of which he took a leg and breast. In the afternoon he went out riding, and returned in his usual health. No supper was taken, but about half past ten in the evening he began to complain of the old disagreeable feeling about the stomach, and he swallowed three tumblerfuls of a hot infusion of thistle. As this did not act with its usual efficacy, he took four more glasses of the same infusion, but still without effect. Much surprised at this, the Baron ordered another dose to be prepared, and in the meantime strove to excite vomiting by tickling his fauces. Whilst straining violently he suddenly felt a horrible pain, and gave such a cry of anguish that his servants hastened to his assistance. He exclaimed that something had burst or been violently displaced near the pit of the stomach, and that he was sure he must die immediately. He was put to bed in a state of utter prostration, being pale, bathed in cold sweat and pulseless. Half an hour after the seizure he swallowed four ounces of olive oil, and with the help of his finger succeeded in vomiting some of the oil together with a certain quantity of the thistle-infusion. Two ounces more of olive oil, however, produced neither nausea nor vomiting, and the pain increased. Shortly afterwards the Baron drank about six ounces of warm spruce-beer.

On his arrival Boerhaave found the Baron sitting in bed, with his body bent forwards almost double. Three servants supported him in this attitude, as every other posture, especially sitting or standing upright, caused excruciating agony. On examining his patient, Borehaave found that there was nothing to be seen in the throat; there was no nausea; scarcely any eructation, the breath was not offensive, there was neither pain nor difficulty in swallowing, there was no thirst, and the feeling of weight about the stomach was no longer present.

No swelling or hardness could be detected in the chest or abdomen. The urine was natural, and could be passed without difficulty. The patient's body seemed to be of normal temperature, the pulse quick and full, but regular, the breathing and sound of the voice natural. There was frequent deep sighing, but no cough. The colour of the Baron's face was natural, his mind was quite clear, and there was no paralysis. In short, the only sign of disease was the agonizing pain felt by the patient, and an indefinable sense of some change in the situation of parts within the chest. The pain was situated at first in the epigastric region and was described by the patient himself as a feeling of some sensitive membrane having been torn; it never ceased, and hardly abated for an instant. Later on, the pain, without leaving its original seat, extended backwards, then along the sides, and finally over the whole inner wall of the chest. The patient stated that flatulence caused extreme suffering, the gas apparently not finding its way up; he could feel it leave the stomach, and then almost immediately experienced an excruciating pain in the chest. The physician 
in vain sought for a satisfactory explanation of the phenomena, the possibilities of "internal inflammation," thoracic tumour, displacement of parts, poison, and gout being successively considered and dismissed.

Boerhaave was inclined to give a hopeful prognosis from the absence of any symptom of disease except pain, which, in spite of its atrocious severity, he did not think would be sufficient to cause death. With the view of diminishing his agony the patient was bled almost to syncope, but this measure failed to give the slightest relief. Poultices, applied near the stomach, made his sufferings worse. Anodyne draughts were administered, but the use of narcotics was avoided, as tending to lessen excretion. The bowels were emptied by enemata. The voiding of urine was diminished to a few drops, passed with great straining and a sensation of scalding. The urine was thick, red, and strong-smelling, these characters proving to Boerhaave's mind that none of the abundant quantity of fluid which the Baron had swallowed could have reached the kidneys. The heart now (sixteen and a half hours after the seizure) began to fail, the face grew pale, the extremities cold, the breathing became hurried, and though the patient's mind continued clear, death seemed imminent from mere exhaustion. As a last resource, thinking that possibly the cardiac orifice of the stomach was obstructed by undigested food, Boerhaave ordered two ounces of sweet almond oil, to be followed by seven ounces of warm water, and directed that the action of the remedy should be assisted by tickling the fauces with a feather dipped in oil. As the result of this, a little liquid was thrown up, but none of the oil returned, and no relief was obtained. Here it may be mentioned that there had been no hiccough during the whole course of the affection. Boerhaave was still inclined to believe that the upper orifice of the stomach was blocked up ; on reckoning up the large quantity of drink taken by the patient and the small amount vomited up or passed as urine, it seemed clear that the fluid could not have reached the stomach. A swelling was now observed in the epigastrium, which seemed to confirm this view. Shortly after the administration of the last emetic, eighteen and a half hours after the beginning of his cruel suffering, the Baron showed signs of collapse, and, rather to the surprise of his physician, suddenly expired.

Autopsy twenty-four hours after death.-A large livid stain was seen on each side of the thorax, with black patches here and there. There was emphysema all over the front and sides of the chest. The abdomen was inflated and extremely tense. On opening it, the peritoneum, intestines and stomach were all found enormously distended with air, but to Boerhaave's extreme amazement, the latter viscus contained only a few drops of reddish-brown fluid. The bladder was empty and contracted. On opening the chest cavity Boerhaave, who at the time knew nothing of the nature of the patient's last meal, remarked a strong smell of roast duck. The pleural sacs were found distended with gas, the lungs collapsed and almost bloodless. In each side of the chest there was a large quantity of fluid resembling that previously seen in the stomach, mixed with some of the thistle-infusion. Floating on this was the almond oil ordered by Boerhaave, but on careful examination, not a drop of blood or pus could be seen. The fluid collected from both sides of the chest measured $104 \mathrm{oz}$. (Amsterdam measure). On the part of the pleura covering the left side of the oesophagus, at a distance of two inches from the diaphragm, there was a discoloured patch about three inches in diameter, in the middle of which a fissure was perceived half an inch in length, and three lines in breadth. The fissure was found to communicate with a space in the mediastinum, from which the retracted ends of the ruptured oesophagus had been drawn asunder in opposite directions. The most minute inspection failed to show the least sign of ulcer or other disease in the oesophagus ; Boerhaave emphatically states that, though he searched in the expectation of finding some pre-existing lesion of the gullet-walls to explain so unprecedented an accident, the more he looked at the edges of the rent and the surface of the oesophagus near them, the more perfectly healthy they seemed to be. The stomach was also quite free from disease. 
Since 1723 upwards of 50 cases of spontaneous rupture of the oesophagus have been recorded in the literature, but because the accident is so rare it is seldom even considered as a possibility in the differential diagnosis of acute thoracic and abdominal emergencies. A wider knowledge of the condition would, in fact, lead to a correct solution in many cases because the history and the clinical manifestations are so similar in most instances that, taken in conjunction with certain special diagnostic features, they offer almost conclusive proof.

The literature has been reviewed from time to time, and notably by Fitz ${ }^{9}$ in 1877, Mackenzie (1884), Walker ${ }^{25}$ in 1914, Smead ${ }^{32}$ in 1931, Ridgeway and Duncan $^{42}$ in 1937, and Terracol (1938). All have virtually the same tale to tell, and none can offer a full and convincing explanation of the observed facts. The subject is again ripe for discussion because it is conceivable that thoracic surgery may now have opened up the way leading to a cure of at least some of these patients.

\section{Definition}

As early as 1877 Fitz $^{9}$ made it clear that "there exists the certainty that a previously healthy oesophagus may be suddenly ruptured by muscular violence," and I stress that the group of cases under discussion does not include any in which perforation has occurred as a result of surgical operations or war wounds. It excludes perforations due to congenital abnormalities, oesophagitis, peptic ulceration, diverticulum, tuberculosis, syphilis, aneurysm, cancer, or any other pathological conditions. In this paper the terms "perforation" and "rupture" are used synonymously.

The reasons for drawing this line of demarcation are threefold. In the first place, the diagnosis of perforation of an oesophagus which is known to be the seat of pre-existing disease, or which has been damaged at oesophagoscopy, is relatively easy because attention is already focused upon the part. In spontaneous perforation the diagnosis has practically always been missed because there is no reason to suspect a lesion of the oesophagus. Secondly, spontaneous perforation of the healthy oesophagus is not a condition within the ken of most surgeons, and, if it were, they would probably make the diagnosis and act accordingly. Finally, perforations due to endoscopic examinations, tuberculosis, carcinoma, etc., are not so fulminating because in them violent vomiting does not occur and consequently the gastric contents are not forced through the tear into the mediastinum and the pleural cavity. Extension of such an inflammation into the pleural cavity causes an empyema, and if this or the mediastinal abscess be adequately drained the patient has a good chance of surviving. Indeed, many cases of this type are on record in which the whole sequence of events has been relatively slow and the lesion has ultimately been controlled (Phillips (1938), Ballin and Saltzstein (1922), etc.). A very small spontaneous perforation may, on occasion, behave in the same way, but this is the exception and not the rule. 
Some peptic ulcers of the oesophagus are clinically and radiologically silent ; this point has been stressed by Negus, Chevalier Jackson, and others, so that the condition may be present when it is not suspected. It is also known that a peptic ulcer may perforate " out of the blue," and the effects of such an accident may be identical with those about to be described in this paper. In scrutinizing the recorded cases only those in which there is no evidence of pre-existing disease should be included in the category of true spontaneous perforations ; but, even so, there remain some in which an element of doubt exists. In 1912, for instance, Gordon Watson" ${ }^{24}$ described two examples of "perforations of the oesophagus due to peptic ulceration." One of these undoubtedly had a pre-existing oesophageal ulcer, but the other is, in my view, a typical example of true spontaneous perforation. This point is mentioned in order to stress the fact that to attempt to differentiate between the two groups of cases may sometimes be rather academic. The patient described by Heller ${ }^{44}$ is another example of this borderline group, for, although the oesophagus in the vicinity of the perforation appeared normal to the naked eye, there was said to be microscopical evidence of pre-existing acute peptic ulceration. Benson and Penberthy (1938) described a case which has been classed by others as a true spontaneous rupture cured by intercostal pleural drainage. But this patient was a child, aged two, who was suspected of having swallowed a foreign body. Eight days after admission the child was cesophagoscoped, and an ulcer, $1 \mathrm{~cm} . \times 1 \mathrm{~cm}$. was seen in the left lateral wall about $1 \mathrm{in}$. above the cardia. After the operation "the child strained considerably and vomited," and four hours later a perforation had occurred into the left pleural cavity. A tension pneumothorax developed and this was treated by closed intercostal drainage. After the operation the child was slowly restored to health, and 21 months later there were no symptoms referable to the thoracic viscera.

Many spontaneous perforations must, in the past, have been missed altogether, even though a post-mortem examination may have been made. For this there are several reasons. In the first place the perforation may be small and, if the oesophagus be slit open after its removal from the body, the incision may pass right through the lesion. Unlikely as this may seem it probably happened in one of the three cases I shall describe (Cleland's case), for in other respects this case was quite typical of spontaneous perforation. To avoid this mistake the gullet should be distended with fluid before it is opened if the perforation cannot be visualized from the pleural cavity. Secondly, necrosis and gangrene of the structures in the posterior mediastinum, together with post-mortem autolysis of the oesophagus itself, may fog the issue if the patient survives for any length of time.

To sum up these points, one may say that spontaneous rupture of the previously normal oesophagus does occur. It is a rare but definite clinical entity. It is worth trying to differentiate these cases from perforation due to a peptic ulcer or other pathological lesions in order to throw the condition into the limelight and so to enhance the possibility of early diagnosis. 


\title{
3. CASE Histories
}

\author{
CASE 1.-N. R. Barrett's Case
}

R. B., a policeman, aged 40, was admitted to hospital on March 10, 1945. There was nothing relevant in the past history and he had been perfectly well until 7.45 on the morning of his illness. At that time he was lying in bed when he experienced a sudden desire to vomit and brought up about half a pint of dark-brown material. This was followed almost immediately by a sharp pain in the back, which radiated round the sides of the chest and both sides of the abdomen. He summoned his doctor, who diagnosed a perforated gastric ulcer and arranged for him to be transferred immediately to hospital.

Upon admission he was in a state of collapse. His pulse was thin and was recorded at 84 to the minute, temperature was subnormal, and he was pale and sweating profusely. He continued to complain of severe pain in the upper abdomen, and he lay still upon his back as though afraid to move. There was no previous history of vomiting or of haematemesis.

The physical signs were judged to be typical of a perforated gastric ulcer, and, after a short period of resuscitation, he was operated upon by the Surgical Registrar. Prior to this operation his chest had been examined by a physician and no physical signs had been detected. At laparotomy the peritoneal cavity was found to be normal and there was no evidence of perforation or of peritonitis. The abdomen was therefore closed and he was given a transfusion of two pints of blood.

Next day $(11 / 3 / 45)$ his general condition had deteriorated and he was thought to have developed some measure of acute dilation of the stomach. His stomach was accordingly washed out, and one and a half pints of dark blood-containing fluid was evacuated. This caused a considerable increase of pain and restlessness, but no abnormality in the thorax was suspected. His chest was not examined, but his chart showed a steady rise in the respiratory rate and he was cyanosed. He still complained of severe pain.

$12 / 3 / 45$. - He had by now developed all the signs of a total pneumothorax on the right side and the mediastinum was markedly displaced to the left. Air was taken off on two occasions ; on the first $1,000 \mathrm{c.cm}$., and on the second 1,660 c.cm. This treatment produced only temporary alleviation of symptoms, and the general condition was serious. He was restless, thirsty, and anxious.

$13 / 3 / 45$. - A needle in the right pleural cavity registered pressures of $+5+15$, and after $800 \mathrm{c.cm}$. of air had been taken off the final reading was $-2-8$; but this relative negative pressure was not maintained, and it was obvious that a valvular leak of some kind must be present. A needle was therefore fixed in the pleural cavity in the second right interspace anteriorly, and through this air discharged intermittently under water into a bottle at the bedside. The patient was given oxygen, and a radiograph of the chest was secured. This showed total atelectasis of the right lung and some air and fluid in the right pleural cavity. The mediastinum was central. Throughout this day the patient was restless and continued to complain of pain in the upper abdomen. The diagnosis remained obscure, but it was suggested that a peripheral lung abscess might have ruptured into the pleural cavity.

$14 / 3 / 45$. $-700 \mathrm{c.cm}$. of turbid fluid was aspirated from the right pleural cavity, but the only test made upon this fluid was bacteriological. The predominant organisms were pneumococci.

$15 / 3 / 45$. - The chest was needled again and $300 \mathrm{c.cm}$. of offensive blood-stained purulent fluid were drawn off A radiograph was then taken, and this showed that in spite of aspirations the volume of fluid in the right hemithorax was increasing rapidly. The patient's general condition remained in statu quo and no additional treatment was given.

$16 / 3 / 45$. - For the last forty-eight hours the needle in the front of the chest had been kept in position and air had persistently bubbled off. I saw the patient in consultation on this day and found an extremely ill man suffering from a tension pyopneumothorax. He was 
dyspnoeic, cyanosed, and restless, and complained of persistent pain and thirst. There were no physical signs apart from those in the thorax ; it was my opinion that the primary lesion was probably in the right lung and that a broncho-pleural fistula was present. There was no cough or sputum, however, and the left lung was normal. There was no surgical emphysema.

More efficient drainage was instituted. The pleural cavity was drained by an intercostal catheter connected to a water seal, and a fine apical tube was inserted and connected to a suction apparatus. During the next three hours twelve pints of turbid watery brown fluid ("smelling not unlike vomitus") drained from the chest and a radiograph showed considerable re-expansion of the collapsed lung. The general condition of the patient was much improved in every way. I did not see the patient again.

17/3/45.-Next morning the clinical condition had again deteriorated. Twenty-one pints of fluid had drained from the right pleural cavity in twenty-four hours, and any further operative treatment was considered to be out of the question as the patient seemed moribund.

$18 / 3 / 45$. - Contrary to expectation his general condition had improved somewhat and continuous suction had caused the right lung to re-expand, so that only a small apical pocket was apparent on $x$-ray examination. The basal catheter was functioning well and nine pints had drained from the chest; this fluid was thin watery brown material. 100,000 units of penicillin were put into the apical pocket.

19/3/45.-At 5 a.m. he experienced a sudden pain in the right chest and screamed out several times. Five minutes later there was a gush of two to three pints of fluid from the basal drainage catheter. His pulse became uncountable and he was profoundly shocked. Throughout the day his condition deteriorated, and at midnight he died. The drainage from the catheter had been nine pints in twenty-four hours. Suction, pleural drainage, oxygen therapy, and the exhibition of penicillin :were maintained until the end. Up to the time when the patien $\hat{\imath}$ died no diagnosis of the basic cause of his illness had been made.

A post-mortem examination was performed on the day after death. The body was that of a well-developed man, and no superficial abnormality was detected. On opening the thorax the right pleural cavity was found to contain about three pints of loculated foul-smelling purulent fluid. The right lung was atelectatic and there was no evidence of lung abscess, broncho-pleural fistula, pulmonary suppuration or tuberculosis. The left pleural cavity and the pericardium were normal, but the left lung contained areas of septic bronchopneumonia. The oesophagus was much autolysed by post-mortem changes, and it was at first difficult to locate the exact site of the perforation. It was small, inconspicuous, and just above the diaphragm. There was no evidence of any pre-existing oesophageal disease, and there was no generalized mediastinitis. The abdominal cavity and viscera were normal apart from an acute haemorrhage into one suprarenal gland, and a nutmeg liver.

\section{COMMENT}

This case has been recorded in detail because it shows only too clearly the pitfalls into which we fell and into which others faced with the same problem have fallen before us. We did not know that spontaneous perforation of the oesophagus could occur, and had we done so we might have saved this man's life by early thoracotomy.

Several points are worthy of special mention.

Some of the enormous volume of fluid which drained from the right pleural cavity may have been regurgitated from the stomach into the oesophagus, but the patient was desperately thirsty throughout, and he drank 12 to 15 pints of 
half-strength saline every day, and much of this fluid undoubtedly passed straight into the pleura.

As there was no mediastinitis in this case the early signs and symptoms must have been due to the harmful effects of gastric contents upon the pleura. It is also reasonable to assume that the man lived for eight days because the perforation communicated directly between the oesophagus and the right pleural cavity in such a way that the mediastinal tissues were sealed off.

Some have thought that adequate pleural drainage alone might save life and tide such a patient over the emergency. In this case I am satisfied that drainage and suction were adequate at least until a short time before death ; but the patient died in spite of this.

Although the diagnosis was not made ciuring life, and even at the post-mortem examination the perforation was small and inconspicuous, the clinical history is such that no other explanation would fit the facts. The story of the onset of the pain following immediately upon the vomiting, the physical signs mimicking perforated gastric ulcer, the early development of a spontaneous pneumothorax, the rapid accumulation of thin brownish fluid in the pleura, and the evidence that more than 50 pints of this fluid drained from the right chest in the last four days of life should have led to a correct diagnosis.

CASE 2.-This case was treated by R. W. Dix, F.R.C.S., of Sudbury.

The patient was also seen by R. Reid, F.R.C.S., of Colchester

L. C., aged 45, an electrician on an aerodrome, returned home from work at about 10.30 p.m. on April 10, 1944, having had a large midday meal, and, later on, two pints of beer and some rum. He refused supper as he had had some sandwiches with his beer, and he went to bed about 11 p.m. telling his wife that he felt sick. Later he came downstairs, and shortly afterwards called his wife, who found him groaning on the floor and complaining of severe pain in the back of the abdomen. He had vomited a small amount. There was no history of difficulty or pain on swallowing, nor of dyspepsia, nor of intemperate habits.

On examination the man was obviously in very great pain and was holding his sides. Movement seemed to increase the pain because he resented being turned for the purpose of examination. He was pale and sweaty, his temperature was $97^{\circ} \mathrm{F}$., his pulse rate 64 , and respirations 22. The abdomen was immobile and rigid and generally tender, but so great was the rigidity that it was impossible to discover whether there was deep tenderness in any particular area or rebound tenderness. As he complained of severe pain in the back and chest a detailed examination of his lungs was made, and no abnormal physical signs were found on either side.

The patient was transferred to hospital, where his temperature and pulse were the same as when first seen. There was no change in the physical signs, and a provisional diagnosis of perforated gastric ulcer was made.

At about 1 a.m. the abdomen was opened under a general anaesthetic, and nothing abnormal was found except spasm of the lower part of the ileum, which was contracted like a cord for a distance of several feet. This spasm relaxed under the anaesthetic. The abdomen was closed and the patient returned to bed. From that time his condition gradually deteriorated and he died twenty-four hours later.

At post-mortem examination the body was found to be well nourished, and there was no discoloration apart from post-mortem changes. There was an area of surgical emphysema 
at the base of the neck in both supraclavicular regions. Nothing abnormal was found in the abdomen. The stomach was still full of a large meal with whole peas and large pieces of onion. When the chest was opened, gas gushed out from the right pleural cavity, which was found to contain, besides gas, a large quantity of dirty-brown fluid with white fibrinous exudate and much undigested food, unmasticated and containing peas, beans and onions, similar to the stomach contents. The right lung was totally collapsed, its surface was injected and covered with patches of fibrinous exudate. The mediastinum was grossly distended with haemorrhagic exudate, and on the right side a tear was found in the pleura overlying the oesophagus about $2 \frac{1}{2}$ in. above the diaphragm. Within this tear, which was 1 in. long, an opening $\frac{1}{2}$ in. long was seen in the oesophagus. A probe passed up the oesophagus could easily be seen from the pleural cavity. The oesophagus at this point felt quite normal. Nothing was found suggestive of ulcer or new growth. The left side of the chest was normal except for congestion of the lung, and patchy fibrinous exudate on the diaphragmatic surface of the lung. The lower two-thirds of the oesophagus were removed for examination.

The microscopical report upon specimens taken from the oesophagus near the perforation reads as follows: "Acute inflammation, shown by fibrinous exudate and infiltration with neutrophil leucocytes, lymphocytes, and macrophages, affects the scanty amount of mediastinal connective tissue present, and is assuciated with areas of necrosis which are undergoing digestion and which are contaminated in places with food. Acute inflammation affects the external part of the muscularis where in places it is associated with necrosis of the muscle. In association with necrosis, digestion, and contamination with food, acute inflammation is also present throughout the muscularis and submucosa at one end in two of the portions of tissue sectioned, this end being the border of the perforation. Slight inflammation and oedema is seen in the remainder of the muscularis and in most places in the submucosa and mucosa ; it is shown by infiltrating lymphocytes and macrophages and, in the mucosa only, some plasma cells. The muscularis mucosae is hypertrophied. In most places the surface epithelium is absent, and in the remainder one to four layers only of epithelial cells are present and many of the cells are in mitosis. Where the epithelium is absent the exposed mucosal connective tissue is superficially digested in places and undigested in others."

\section{COMMENT}

Mr. Reid has sent me the following observations about this case. "These are the original notes I made after the post-mortem examination with Rix. I saw the man a day after his operation, and he was then grey, sweating, and so ill that nothing could be done. I would say that spontaneous perforation of the oesophagus is very like rupture of the gut into the general peritoneal cavity. With regard to the cause of death, I think some toxic absorption must occur from the virgin pleura and this absorption is so rapid that the patient is overwhelmed. I have now had experience of two subphrenic abscesses which suddenly ruptured into the peritoneum and of another which burst through into the pleural cavity ; the patients died an acute toxic death. They died far more rapidly than would a person who had ruptured his stomach or intestines."

\section{CASE 3.-This case was seen and treated by Dr. W. P. Cleland, M.R.C.P., of Horton War Hospitai}

This was a man, aged 60 , who had apparently been quite well until the evening of April 2, 1945. He had several pints of beer before dinner, but did not have an excessive 
meal. Shortly after dinner he felt sick and went upstairs, where he vomited profusely. On his way downstairs he noticed a swelling in his neck, and he was quite certain that he had no pain of any sort at this moment. After this his condition rapidly deteriorated and he soon became so acutely ill with abdominal pain that he was admitted to hospital. The first diagnosis was perforated gastric ulcer; this was based on the acute abdominal state and the fact that the patient was collapsed by this time. Surgical emphysema did not, however, fit the picture, and it was decided to adopt expectant treatment. His condition did not give rise to any undue alarm during the night, but by the following morning his temperature had risen to $104^{\circ} \mathrm{F}$.

He was first seen by Dr. Cleland at 2 p.m. No treatment, apart from the exhibition of morphia, had been prescribed up to this moment. He was then acutely ill, pale, sweating, cyanosed, and still suffering from acute abdominal pain. When questioned as to his history he was noticed to be rather incoherent and was very restless. His pulse was weak, thin, and rapid. His mouth was dry and furred and his respiratory rate markedly increased.

Clinical examination revealed gross surgical emphysema of the neck and upper chest and the air was distributed slightly more upon the right side of the body than the left. The trachea was central and the apex beat imperceptible. There were good vesicular breath sounds over the whole surface of the left lung but upon the right side it was difficult to hear breath sounds on account of the emphysema. There were no physical signs to suggest any abnormality in the abdomen.

A radiograph of the chest was taken, and this showed marked surgical emphysema, good aeration of both lungs and no definite evidence of a pneumothorax on either side. There was, however, a fluid level at the right base with increased haziness in this area, and also moderate effusion at the left base.

The right chest was needled anteriorly. A pressure of $-2+4$ was found; about $500 \mathrm{c.cm}$. of air was taken off without any alteration in the patient's condition and there was no change in the pressures at the end of aspiration. After this a needle was inserted low down in the right axilla and thin brownish turbid fluid was obtained. The fluid had a slightly sour smell but was not offensive; it contained a deposit of about $10 \%$ of pus.

Dr. Cleland diagnosed spontaneous perforation of the oesophagus and inserted an intercostal tube into the right pleural cavity. From this tube three pints of fluid straightway drained off. The patient's condition deteriorated and he died at 5 p.m. on April 3.

Post-mortem.-There was marked surgical emphysema of the chest wall, of the tissues of the neck, and of all the mediastinal structures. Both pleural cavities contained brownish fluid, about three pints being present on the right side, and this fluid was exactly similar to that found in the stomach. Acute haemorrhagic inflammation of the pleural membranes was present, and this was particularly marked in the right chest, which showed striking purple and red mottling. There were fusiform areas of necrotic mediastinal tissue around the oesophagus extending from the bifurcation of the trachea to the diaphragm; the pleura over this was necrotic. The oesophagus was unfortunately opened before it had been distended, and although no definite rupture could be seen there were several areas in which this might have been present. There was little doubt that the perforation was low down in the oesophagus, for it was in this area that the maximal changes were found in the mediastinum.

\section{COMMEnT}

This case is interesting for many reasons. In the first place there was at first no history of signs and symptoms referable to the abdomen; this is most unusual. Secondly, the patient was quite definite in his statement that pain was not present until a little time after surgical emphysema had appeared in the neck. There are other cases in the literature in which pain did not occur immediately. In the case 
reported by $\mathrm{Fitz}^{9}$ it was deferred for some hours, indicating probably that rupture did not take place at the first onset of symptoms. Thirdly, the early development of surgical emphysema, and finally the rapid march of events towards a fatal issue.

Dr. Cleland made the following observations about this patient: "In my view this man died from spontaneous rupture of the oesophagus, and neither in the history nor in the subsequent findings was there any evidence of a pre-existing organic oesophageal lesion. The rupture must have been due to vomiting. It might have been possible to do a thoracotomy if adequate resuscitation had been practised early ; as it was, the man was so ill when I first saw him that operation was out of the question. A diagnosis of rupture of the oesophagus was made because three things seemed to favour this: surgical emphysema, a bilateral pleural effusion of sudden onset, and the great speed at which fluid was accumulating in the pleural cavities. It would certainly have been possible to demonstrate this rupture at autopsy if the oesophagus had been properly tied off and dilated with water before it was removed from the body. It is also possible that if both pleural cavities had been drained the patient might have recovered, especially as the perforation in the oesophagus was very small and probably functionally closed." My own experience would lead me to disagree with this last opinion, because gross contamination of the mediastinum had already occurred.

\section{Pathology of Spontaneous Perforation of the Oesophagus}

Rupture practically always occurs just above the diaphragm at the bottom of the oesophagus, and although the lower limit of the tear may impinge upon the gastric mucosa, there is only one case on record in which the lesion involved the peritoneal cavity or the retroperitoneal tissues. This was reported by Sencert ${ }^{23}$; his patient was a woman, aged 28 , whose abdominal oesophagus ruptured whilst she was quietly reading one afternoon. She died of peritonitis. Allen (quoted by Terracol) is said to have reported a case in which rupture occurred at the level of the bifurcation of the trachea, but this record also stands alone.

In general the perforation is disposed in the long axis of the gut ; it is between 1 and $8 \mathrm{~cm}$. in length, and is situated in the left posterolateral aspect of the circumference. It will be remarked that in two of the cases I report the rupture could not be clearly demonstrated at autopsy, and it is apparent that a spontaneous perforation can be very small and yet lead to the full train of symptoms, to rapid accumulation of much fluid in the pleural cavities, and a fatal termination. If the rupture happens to be on the right side of the oesophagus it is generally situated about $6 \mathrm{~cm}$. above the diaphragm.

Transverse tears have been recorded on a few occasions; these have also occurred in the lower oesophagus, and when present there is a strong tendency for both pleural cavities to be inundated with gastric contents. Michel (1880), who translated Boerhaave's original paper, says that in this case the transverse tear 
was so complete that the two ends of the oesophagus were widely separated from each other, and the lungs, collapsed and discoloured, were "swimming in pools of liquid similar to that found in the stomach." Generally only one tear has been found, but in Raestrup's ${ }^{30}$ case there were two ; only the longer of the two had actually perforated right through into the pleural cavity. Gramatski's ${ }^{5}$ case was very similar to Raestrup's.

Why the lower end should be the seat of election has been the subject of much controversy. Mackenzie (1884) has shown experimentally that the weakest part of the oesophagus is at the extreme lower end, and longitudinal tears can be produced in this area by raising the pressure inside the gut with fluid or gas. The disposition of the musculature and of the blood vessels in the wall of this part of the gut, and the transition from one type of epithelium to another may be factors predisposing to this weakness. Many experiments were conducted upon cadavers by Mackenzie (1884) to ascertain the actual pressure necessary to burst the healthy oesophagus, and a force of between 5 and $10 \mathrm{lb}$. per square inch seems to be that which is generally needed; but there are obvious objections to such assays, and the figures can only be approximate. Mackenzie drew the following conclusions from his experiments: (1) that rupture always takes place in a longitudinal direction; (2) that the rent never occurs in the upper half of the gullet; (3) that the mucosa offers greater resistance to strain than the muscle coats. The left side of the oesophagus is much more commonly affected than the right, presumably because at the extreme lower end the right side is supported to some extent by the thoracic aorta and retropericardial fat, whilst the left lies immediately under the parietal pleura. Below the diaphragm the short stretch of the abdominal oesophagus is buttressed by the "liver tunnel" and the fundus of the stomach.

The macroscopic appearances of the perforation itself and of the surrounding tissues have been carefully studied, and although variations are to be expected the consensus of opinion is that the lesion occurs as a result of a sudden increase in pressure inside the healthy oesophagus; it looks as though the wall of the gut has been "cut with a knife" (Fitz, ${ }^{9}$ Lindsay, ${ }^{15}$ etc.). Microscopic examinations have repeatedly confirmed this opinion, and especially is this so if the patient has died within 12 hours of the onset of symptoms. In those who have survived longer the mucosa of the oesophagus may be excoriated in the vicinity and the tissues infiltrated with inflammatory cells. In a series of animal experiments Williams and Boyd ${ }^{29}$ showed that, after artificial perforations, these post-mortem appearances are not due to autolysis but to an acute inflammation evoked by the presence of acid gastric juice and bacterial infection in the mediastinum.

In some cases, complete perforation, straight through into the pleural cavity, does not occur immediately (Girard, ${ }^{38}$ Sheldon, ${ }^{27}$ Ridgeway and Duncan, ${ }^{42}$ Collis, ${ }^{51}$ etc.). Weiss and Mallory ${ }^{34}$ describe such a case. It occurred in a man, aged 30, who had been drinking synthetic gin in large amounts for eight days. 
The onset of symptoms was gradual, with retching, vomiting, and several small haematemeses. Soon after admission the patient had three large haematemeses and died within 24 hours. At autopsy a longitudinal tear, $2.5 \mathrm{~cm}$. long, was found at the lower end of the oesophagus, but this had not extended right through to the surface of the muscle coats. Death had been caused by bleeding from a vessel exposed in the edge of the rupture ; there was no evidence of local or generalized oesophagitis, and the pleural cavities were normal.

Although haematemesis has not commonly been recorded in the literature, blood-stained fluid has often been found in the mediastinum and pleural cavities. This is to be expected, because in the lower reaches of the oesophagus there is a free anastomosis between the oesophageal vessels coming from above and branches of the left inferior phrenic and left gastric coming from below. Varices are commonly found here in conditions such as hepatosplenic cirrhosis.

In some cases rupture involves the pleural cavity directly and the mediastinum is not contaminated. In these it may reasonably be argued that, however much the history suggests a true spontaneous rupture, some pre-existing perioesophagitis has probably been present and this has walled off the tissue planes.

Another possibility is that gastric contents may be temporarily imprisoned in the posterior mediastinum, the parietal pleura remaining intact for some hours. In some cases a large mediastinal collection of this sort occurs; this tends to be confined between the level of the hilum of the lung and the crura of the diaphragm. In a paper dealing with post-operative perforations Phillips (1938) points out that the various mediastinal spaces do not communicate freely with each other, and that it is rare for perforations of the cervical oesophagus to cause posterior mediastinitis, because there is a partial obstruction to the spread of inflammatory products and extravasated fluid at the level of the hilum of the lung. This barrier is only partial, for when a perforation occurs in the lower oesophagus, gas as well as fluid is forced into the posterior mediastinum, and this produces surgical emphysema which tracks upwards and soon presents in the root of the neck. Collis ${ }^{51}$ operated upon his patient nine hours after the onset of symptoms, having diagnosed the condition correctly, and found that the left pleural cavity contained $8 \mathrm{oz}$. of straw-coloured fluid; the mediastinal pleura was still intact, but confined within this space was a large dark purple cystic swelling. By incising the pleura over this tumour he released about a pint of blood-stained gastric contents and so exposed the perforation in the oesophagus. These observations illustrate another fact of prime importance-namely, that if extravasated gastric contents are held up for some time in the mediastinum a serous effusion develops rapidly in one or both pleural cavities. Such an effusion may contain organisms, but Williams ${ }^{29}$ found that it was alkaline in reaction and had all the properties of an inflammatory exudate.

Other points in connexion with the extravasation of gastric contents into the mediastinum must be stressed. They cause widespread necrosis and gangrene of 
the tissues, and Popper ${ }^{36}$ found in his case that the rupture into the left pleural cavity was not at the same level as the oesophageal perforation. Phillips (1938) stresses that necrosing mediastinitis constitutes the most urgent menace to life, and that few patients seen after 24 hours can have any hope of recovery, whatever treatment be adopted. In some instances a pericardial effusion has been found.

It has already been stressed that an initial serous effusion can occur in the pleural cavities, but, soon after intrapleural rupture has taken place and gas and gastric contents have burst through into this space, a most intense inflammation ensues. In one of the cases I record the vivid hues, ranging from purple to blue, from red to black, were a most striking feature. Aldrich and Anspach ${ }^{45}$ also stress this point, and state that the inflammation appears to be most virulent in those areas which have actually been bathed in the "noxious" fluid. This fulminating pleural reaction is accompanied by pulmonary atelectasis. Tension pyopneumothorax may also develop.

On several occasions as much as a gallon of fluid and partially digested food has been found in the affected pleural cavity. Especially large amounts have been present when gastric lavage has been used or the patient has been encouraged to drink to sate extreme thirst.

\section{(1) Age and Sex Incidence}

\section{Clinical Aspects}

The emergency occurs much more often in men than in women; the proportion quoted by Walker, ${ }^{25}$ who collected 22 published cases in 1914, was 20 men to 2 women. This preponderance in males has been confirmed by subsequent reviewers, and it may be due to the fact that men are more likely to indulge in pursuits which predispose to violent vomiting than are women.

It may be manifest at any age, but most of the patients have been between 35 and 50 years old. The condition also occurs in children, and in 1811 Monro (in his book upon the morbid anatomy of the gullet, stomach, and intestines) stated that he had in his possession the gullet of a child in which rupture had occurred, adding that an example of a similar occurrence had been related to him by Carmichael Smyth, who was physician to the King in Scotland at the end of the eighteenth century. More recently Menne and $\mathrm{Moor}^{28}$ have asserted that during the last 200 years only three undoubted cases have been reported in children. They describe the case of a female child, aged five months, who had always been prone to attacks of vomiting (probably due to overfeeding). Acute symptoms occurred during one of these attacks, which had already lasted for more than 24 hours and during which "a curd of milk became stuck in the throat." Attempts to dislodge this obstruction by further vomiting resulted in a rupture of the oesophagus. The baby lived for 36 hours after this accident and died without a diagnosis being made. At autopsy a longitudinal tear, $3 \mathrm{~cm}$. in length, was found in the lower part of the oesophagus, and the left pleural cavity contained a con- 
siderable amount of stomach contents. There was no evidence of any preexisting inflammation of the parts.

\section{(2) Past Personal History and Aetiological Factors}

In a small proportion of the cases there is nothing in the previous history which could be connected with the onset of symptoms (Kyle's ${ }^{40}$ case is a good example), but in the majority there is a record of violent vomiting often associated with gluttony and alcoholism. The Grand Admiral of Holland was a case in point. It is probable that alcohol predisposes to the condition in two ways: first, because taken in excess it causes retching and vomiting, and, secondly, because it produces inco-ordinated muscle action.

Vomiting is caused by compression of the distended stomach between the abdominal muscles and the diaphragm, and at the critical moment the cricopharyngeal sphincter relaxes. In addition, radiographs show that a strong contraction occurs at the incisura angularis, dividing the stomach into two separate halves (Starling 1920). This widespread series of activities, involving both voluntary and involuntary muscles, depends upon accurate co-ordination of the affected parts, and this co-ordination may be at fault in a patient suffering from acute or chronic alcoholism. Indeed, it is essential to postulate some form of abnormal spasm or temporary obstruction in the upper oesophagus, and probably a full stomach, in order to account for the rise of pressure inside the gullet which must precede perforation.

Although it is not directly relevant to spontaneous perforation of the cesophagus, there is another way in which persistent vomiting might cause rupture. Vinson ${ }^{33}$ has reported a series of six cases in which continued vomiting of pregnancy caused acute lesions in the lower part of the oesophagus ; in these patients strictures developed at a later date and required treatment. Any of these patients might have perforated.

It would be comforting to know that spontaneous rupture of the oesophagus only threatened the glutton and the chronic alcoholic, but unfortunately this is far from being the case. There are in fact a number of miscellaneous aetiological factors which have been reported. The accident may occur after a heavy meal in which no alcohol has been consumed, or it may result from an occasional lapse from grace. Popper ${ }^{36}$ records the fate of a postman, aged 45, who was an abstainer, but who went out to dinner one night, and "against his usual custom took a fairly large quantity of wine and was brought home drunk." He vomited scveral times, and at 2 a.m. violently ; immediately afterwards he felt a sudden agonizing pain in the left renal area, and in less than 24 hours he had died with a perforation of the oesophagus into the left pleural cavity.

Any type of oesophageal obstruction may be associated with perforation of the normal gut below the block if the patient has cause to vomit. The instance of the baby in whom a curd of milk lodged in the gullet has already been mentioned. Vinson ${ }^{33}$ has described an interesting example in a woman who had 
swallowed a small amount of corrosive as an infant. In adult life she had developed a benign stricture, and this had been treated over a period of years by more than 100 oesophagoscopies and a gastrostomy. One day a bolus of food became impacted in the stricture, and in attempting to force this down she retched violently and ruptured the oesophagus between the cardiac end of the stomach and the stricture. Smead's ${ }^{32}$ case is another of the same type. A man, aged 50, was admitted to hospital with signs and symptoms of acute intestinal obstruction. He was known to have had a duodenal ulcer of many years' standing and also a benign stricture of the oesophagus. At laparotomy a volvulus of a loop of the ileum was found and relieved, but the patient never rallied from the operation and 36 hours later he died. Autopsy showed the tear of the oesophagus to be well below the stricture. Immediately prior to the operation he had had a severe spasm of retching, and the oesophagus must have perforated into the left pleural cavity at that time.

Sheldon ${ }^{27}$ describes an example of another kind. His patient was a healthy soldier who was travelling in a troopship and had been seasick on and off for three days. During one of these spasms he was smitten with a severe pain, and, sweating profusely, he collapsed. The "appearances were those of an intensely seasick man," but, as additional signs developed, a diagnosis of intestinal obstruction was made. Before anything could be done to treat this emergency the patient experienced a desire to defaecate, and ran to the lavatory from his bunk. There he collapsed and died within a few minutes. In the left pleural cavity there was a quart of foul-smelling gastric fluid, and the oesophagus had perforated one inch above the diaphragm. Whipple ${ }^{49}$ also mentions a case in which perforation occurred during the act of defaecation.

Klein and Grossman ${ }^{50}$ have recently recorded an unusual aetiological factor. Their patient ruptured the oesophagus, at the typical site, as a result of the sudden increase of intra-abdominal pressure produced by muscle spasm during an epileptic seizure. The patient had just partaken of a large meal.

Indirect trauma can be responsible for the accident. Griffith ${ }^{35}$ quotes a case which may have been due to this cause; it occurred in a man, aged 46, who developed sudden excruciating abdominal pain as he was attempting to lift a 50-lb. bundle. Aldrich and Anspach $^{45}$ describe an even more definite example. A child, aged $4 \frac{1}{2}$, climbed on to a stone mantelpiece, part of which immediately became dislodged. The child fell to the floor and a large piece of masonry crashed down in such a way that it lay across the abdomen. A right-sided pneumothorax was demonstrated by radiographs within eight hours of the accident, but in spite of this, laparotomy was performed and the child died within 48 hours of the accident. The right pleural cavity was full of fluid at the time of death, and the perforation was typical of a spontaneous rupture. Another example is that described by Murdoch ${ }^{31}$; his was a child who had been run over by a motor bicycle, and at autopsy the rupture was found $\frac{s}{d}$ in. above the diaphragm, the 
left lung was atelectatic, and a small amount of fluid was present in the left pleural cavity.

\section{(3) Signs and Symptoms}

In practically every case the onset of symptoms is dramatically sudden, and leads rapidly to a state of acute emergency. It is noteworthy that if the patient has been vomiting or retching prior to this climax, these symptoms generally cease abruptly and the whole character of the picture is dominated by the new developments. The dramatic nature of the rupture is best described in some of the patients' own words. One felt as though some heavy weight was pushing upon his heart ; another said he felt that his heart had burst ; whilst a third was so stricken with abdominal pain that he dared not move for some minutes. Desjardins ${ }^{47}$ makes a strong point of the fact that both his patients (c.f. also Boerhaave ${ }^{1}$ and Sencert ${ }^{23}$ ) were in such agony that they could not lie down, but sat up in bed with the trunk semiflexed and the arms clasped across the lower chest.

The pain, which is of a continuous type, varies in its position and distribution. In some it is centred upon the territory of the xiphoid, in others it passes through to the renal area or to the base of the chest, and in yet others it is felt in the left shoulder and referred from the diaphragm. Excruciating pain is apt to persist until death relieves the patient, and is unaffected by narcotic drugs or by laparotomy. In general, symptoms are referred to the upper abdomen. The complexion is ashen grey with perhaps a tinge of cyanosis, and the patient is restless, anxious, and often complains of intense thirst. On more than one occasion thirst has been so intense that the patient has hastened his own end by drinking freely. The temperature may be subnormal or raised, but the pulse is generally rapid and thin, and the brow moist with perspiration. Upon physical examination there is usually board-like rigidity of the upper abdominal muscles, and the epigastric area may be exquisitely tender. The signs may in fact be very suggestive of a perforation of the gut into the general peritoneal cavity. In these circumstances, a diagnosis of perforated peptic ulcer has generally been made and laparotomy has been the usual treatment.

There are, however, several features which, upon occasion, may serve to differentiate between abdominal and posterior mediastinal emergencies. The most significant of these are that, in the latter, cyanosis, grunting respirations, extreme thirst, surgical emphysema, and persistent pain are common. In perforated peptic ulcers the pulse is typically slow at first, whereas in most of the recorded cases of perforation of the oesophagus it has been noted that in the early stage it is thin, thready, and rapid.

Every surgeon who is called upon to treat abdominal emergencies examines the hernial orifices and the chest, and one might have hoped that by practising this routine false diagnoses could be avoided in the case of spontaneous rupture of the oesophagus. Unfortunately this expectation is seldom fulfilled, and it is of 
cardinal importance to realize that in the first few hours there may be few if any local signs to point to the fact that a rupture has occurred into the pleural cavity. Indeed, a study of the available records leads to the dismal conclusion that it is not until the patient has almost passed beyond the possibility of recovery that a pyopneumothorax is clinically obvious. This partly accounts for the fate which has, up to the present, overtaken all the recorded cases. In spite of this, it is my conviction that if the condition were widely known the diagnosis from abdominal emergencies would be achieved with more certainty and some patients might be saved, for there are definite pointers.

The earliest signs in the chest are crepitations which are probably pleural in origin, and these are followed by absent breath sounds and a flat percussion note at one or both bases. Cyanosis has already been mentioned, and this, taken in conjunction with pain in the upper lumbar area, has sometimes led to a diagnosis of pancreatitis. In some patients the respiratory rate is significantly raised and the breathing may be shallow and grunting. But there is one sign which, when present, is almost pathognomonic, especially if it be taken in conjunction with others referable to the thorax-namely, surgical emphysema. My colleague Mr. R. H. O. B. Robinson tells me that he was called one night to the bedside of a middle-aged woman suffering, as he thought, from a perforated peptic ulcer. The diagnosis was not entirely clear and thinking that the lesion might be acute pancreatitis, for there was cyanosis, he delayed treatment for a short time in order to examine the abdomen again. At his second examination he noted surgical emphysema in the subcutaneous tissues over the clavicle and the posterior triangle of the neck, but the patient died soon afterwards and no treatment was possible. At the time of death the emphysema was extensive and involved the face and the front of the chest. I have little doubt that this woman had a perforated oesophagus, but no post-mortem examination could be obtained to confirm this diagnosis.

Surgical emphysema is by no means always observed, and in many cases it appears late. The reason for this is that its presence in the suprasternal notch and the deep tissues of the neck indicates one of two things: either rupture has not immediately involved the pleura, and the escaping gastric fluids and gas are confined for the time being in the mediastinum (early cases), or the emphysema appears at a time when the pressure in the pyopneumothorax has reached or exceeded atmospheric, and so it is as easy for the gas to pass into the fascial planes as it is for it to escape into the pleura (late cases).

In the final phase the signs are those of extreme collapse associated with total atelectasis of the lung with gas and liquid in one or both pleural cavities.

\section{(4) The Difficulties of Diagnosis}

The diagnosis of spontaneous rupture of the oesophagus is not cut and dried, except in those rare instances when signs which are pathognomonic may be present. Not only does this lesion simulate others which are infinitely more 
ccmmon, but circumstances may combine to put the clinician completely off the track. Such was Whipham's ${ }^{19}$ case ; the patient was admitted to St. George's Hospital drunk and with a compound comminuted fracture of the skull. He died after the head wound had bsen treated surgically, and the perforation of the oesophagus was not discovered until autopsy.

(a) The history, signs, and symptoms can be so suggestive of a perforated peptic ulcer that the possibility of any other pathological condition being responsible is seldom even considered. Indeed, it would be a brave man who preferred the rare to the more usual diagnosis in many of these cases.

(b) Acute pain in the back, abdominal rigidity, tenderness, and cyanosis may strongly suggest acute pancreatitis. Several cases have been diagnosed and treated as acute cholecystitis, and Walker, ${ }^{25}$ who is said by some reviewers to have been the first man to diagnose the condition in life, actually made this mistake himself.

(c) The common history of a large meal, with or without an excess of alcohol, deflects attention from the oesophagus to the abdomen.

(d) Vomiting due to sea-sickness and that due to food-poisoning have both been responsible for errors in diagnosis. My own experience with these conditions convinces me that perforation of the oesophagus might in fact result from the violent spasms and haematemesis which can occur. Girard ${ }^{38}$ reported the case of a man, aged 61 , who had partaken of a large meal of mussels and who was suddenly prostrated with violent retching and severe precordial and epigastric pain. He was diagnosed as suffering from shellfish poisoning and treated with emetics and gastric washouts. He died $8 \frac{1}{2}$ hours after the first seizure. A perforated oesophagus was found with 4 litres of offensive brown fluid in the left pleural cavity. His end had been hastened by gastric lavage.

(e) The relief of vomiting which practically always follows the actual perforation may be construed as a favourable omen even though thirst, pain, and collapse persist.

(f) Violent intrathoracic pain has often led to a primary diagnosis of an acute coronary accident.

(g) At the beginning there may be few or no physical signs in the chest. Case histories underline this point, but it is apparent that many of the patients are so collapsed that the physician has not thought it wise to move them into such a position that a thorough examination of the chest could have been made.

(h) Physical signs, pointing without doubt to atelectasis and pyopneumothorax, are terminal and not early.

(i) Spontaneous pneumothorax, mesenteric thrombosis, infarction of the spleen, rupture of a subphrenic or hepatic abscess, fulminating coccal infections of the kidneys (Cabot, 1936), and dissecting aneurysm of the aorta may also cause confusion in diagnosis. Paul White describes the pain of the 
latter as being of sudden onset, situated substernally or in the back, and of fierce, excruciating, or tearing quality. A point of difference between this pain and that of perforation is that the former attains its acme at the moment of perforation and then wanes, whereas pain due to the latter gets worse and worse in spite of treatment.

Taking these observations into account it is clear that certain tests should be applied whenever the diagnosis seems possible. A radiograph of the thoraxtaken, if circumstances permit, with the patient sitting up-might reveal a pleural effusion or liquid and gas in the pleural cavity ; a penetrating film might show a fusiform opacity and possibly emphysema in the posterior mediastinum or the root of the neck, and if the symptoms were in fact due to an abdominal perforation or to a rupture of a subphrenic abscess into the peritoneum a bubble of gas might be apparent below the diaphragm. Secondly, the suspected side should be needled. If serous fluid be withdrawn the diagnosis is at least a possibility and a laparotomy is contraindicated; whereas if blood-stained gastric contents be obtained the diagnosis is certain. It is a curious fact that few who aspirate gastric contents from the chest (as, for example, from the stomach in an unsuspected diaphragmatic hernia) ever suspect the true nature of the material they have drawn off ; it may even be labelled "grumous fluid" without the significance being realized. The pleural fluid in cases of spontaneous rupture generally contains blood, but this blood has been acted upon by gastric ferments and undergoes changes in consistency, colour, and smell. It is in fact described as having a dirty brown appearance and a sour odour. This point is of diagnostic importance, for a similar condition of profound shock associated with fluid in the pleural cavity can be caused by spontaneous haemothorax, and the latter condition is not uncommon. Here, however, the blood is of normal appearance. A clinical search should be made to discover surgical emphysema in the suprasternal notch, the posterior triangle of the neck, or upon the upper part of the front of the chest. Finally, there is a place for oesophagoscopy, as a pre-operative procedure, if there is an insoluble doubt between perforation of an abdominal peptic ulcer and perforation of the oesophagus.

The whole question of the clinical presentation, and of the reasoning which should underlie the diagnosis, of spontaneous perforation of the oesophagus has been most ably discussed by Mallory (1940) and his colleagues at the Massachusetts General Hospital (Case No. 26061).

\section{TReatMent}

Not having diagnosed or treated one of these cases accurately I cannot do more than propound certain principles for criticism. Successful treatment depends upon early and accurate diagnosis, and herein lies the rub. In this whole series of case histories, the diagnosis has only been made a very few times before death and, according to Mackenzie (1884), Meyer ${ }^{4}$ was the first man to recognize the nature of the lesion during life; but encouragement may be had from the fact 
that more success has been achieved recently than ever before. To Mallory (1940) and Collis et al. ${ }^{51}$ much credit is due on this account.

It is certain that, untreated, the patient will die a terrible death within the span of a few days. Ridgeway and Duncan, ${ }^{42}$ who analysed all records up to 1937, report that in a total of 35 patients (all of whom died) one lived 17 days, five lived more than 48 hours, and 29 died in less than 48 hours. The patient reported by Fitz ${ }^{9}$ lived for eight days, during which the sufferer passed through a sharp attack of delirium tremens ; and in instances such as this it is possible that the rent is small at first and only extends later. If these figures be accepted then early surgical repair of the perforation offers the only hope, and it is apparent that speed is even more essential in diagnosis than it is in cases of intraperitoneal perforation.

It is a little obscure why death should generally occur so rapidly, but it seems probable that the mediastinal complications are more responsible for this than are those in the pleural cavities or the lungs. It is known, for example, that traumatic rupture, such as has often occurred as a result of oesophagoscopy. generally kills the patient within 48 hours. Gross contamination of the mediastinum leading to necrosis of the tissues was the apparent cause of death in Collis's ${ }^{51}$ case, for he had successfully closed the perforation in the oesophagus and the pleural cavity had been properly drained. On the other hand, it is fair to point out that some forms of sudden pleural contamination, such for instance as occurs after rupture of a putrid lung abscess, can cause grave symptoms within a few hours. It may be that a large volume of gastric contents, containing as it does ferments, food and hydrochloric acid, may be equally devastating.

With these points in mind I would make the following suggestions. Thoracotomy should be done as soon as the diagnosis can be made, and since the perforation is so constantly at the lower end of the oesophagus the chest should be opened with this goal in view. In most cases a left-sided approach is indicated.

If a mediastinal collection be seen, the pleura over it should be incised and the fluid evacuated so that the oesophagus can be properly examined, and the perforation sutured. In a recent communication, Belsey (1946) has shown once again that stainless steel wire is an excellent suture material whenever it is important to prevent a leak from a tissue which is already the seat of inflammation. Most surgeons would prefer to use one of the more standard suture materials, but it may be worth bearing in mind that wire is the only substance which, in the presence of acute inflammation, is totally ignored by tissues. Thread, silk, and catgut aggravate and perpetuate sepsis; wire does not.

If the perforation in the gullet can be properly closed the next step is to make certain that the mediastinum is drained widely into the pleural cavity, and that the pleural cavity itself is drained by an accurately placed water-seal system. Postoperatively, every effort should be made to get the lung upon the operated side expanded as soon as possible in order to avoid the establishment of a total empyema, and a watch should be kept against the possibility of suppurative 
pericarditis. Morphia, suction with a Ryle tube, and chemotherapy would probably also be indicated.

\section{Conclusion}

In the byways of surgery there can be few conditions more dramatic in their presentation and more terrible in their symptoms than spontaneous perforation of the oesophagus. No case has yet been treated successfully, and diagnosis has only been achieved in a very few before death, and yet there is no fundamental reason why this unsatisfactory position should not be improved in the future. Several ihings are essential to success : firstly, a knowledge that the accident can and does occur ; seconcily, a knowledge of the symptomatology ; and, thirdly, an early diagnosis. Given these, I am convinced that surgeons will be able to save some of these patients by combining the principles, already well established in the case of abdominal perforations, with those relevant to thoracotomy.

In the preparation of this paper I have had valuable help and criticism from R. Reid, M.S., R. W. Rix, F.R.C.S., and W. P. Cleland, M.R.C.P., to all of whom I tender sincere thanks. I would also thank Kathleen Guest for a careful check of the bibliography and of the references.

\section{BIBLIOGRAPHY}

Recorded cases of spontaneous perforation of the oesophagus. Arranged in their historical order. Some of these authors describe more than one case.

${ }^{1}$ Boerhaave, H. (1724). Atrocis, nec descripti prius, Morbi Historia, Secundem Artis Leges Conscripta, Ludg., Batav.

" Dryden, J. (1788). Med. Commentaries, Edinburgh, 3, 308.

${ }^{3}$ King, T. W. (1843). Guy's Hosp. Rep., Ser. 2, 1, 113.

${ }^{4}$ Meyer, J. (1858). Med. Zbg. Berlin, 1, 189, 195, 201.

${ }^{5}$ Gramatski, E. (1867). Inaugural Dissertation, Königsberg.

${ }^{6}$ Griffin, J. (1869). Lancet, 2, 337.

Charles, J. J. (1870). Dublin J. med. Sci., 1, 311.

${ }^{8}$ Bailey, J. S. (1873). N.Y. med. J.; 17, 513 .

${ }^{9}$ Fitz, R. H. (1877). Amer. J. med. Sci., 73, 17.

${ }^{10}$ Taendler (1878). Dtsch. Z. prak. Med., No. 52, 5, 613.

${ }^{11}$ Adams, W. (1878). Trans. Path. Soc., Lond., 29, 113.

${ }^{12}$ Lindermann, M. (1887). Münch. med. Wschr., 34, 493.

${ }^{13}$ Harrison, C. E. (1893). Lancet, 1, 784.

${ }^{14}$ Wolff, L. (1894). Med. News, 64, 516.

${ }^{15}$ Lindsay, J. A. (1899). Trans. roy. Acad. Med. Ireland, Dublin, 17, 51.

${ }^{16}$ Heintze (1900). Itach. med. Wachr., 26, Ver.-Beil., 160.

${ }^{17}$ Bowles, R. L., and Turner, G. R. (1900). Brit. med. J., 1, 763. Also (1900) Trans. roy. Med. Chir. Soc., 83, 241.

${ }^{18}$ McWeeney, E. J. (1900). Lancet, 2, 158.

${ }^{19}$ Whipham, T. R. C. (1903). Ibid., 2, 749.

"N Miller, G. I. (1911). Post-Graduate, 26, 312.

"2. Roy, D. W. (1911). Lancet, 2, 1765.

2: Pinto de Magalhaes, A. C. (1911). Med. Contemp., 29, 177

${ }^{23}$ Sencert (1911). Bull. Mém. Soc. chir. Paris, 37, 1046.

"W Watson, Gordon C. (1912). Brit. med. J., $2,1182$.

${ }^{23}$ Walker, I. J. (1914). J. Amer. med. Ass., 62, 1952.

${ }^{26}$ Watkins, R. W. (1919). Trans. Chicago Path. Soc., 11, 23.

${ }^{27}$ Sheldon, L., Jr. (1919). U.S. Nav. med. Bull., 13, 529.

${ }^{28}$ Menne, F. R., and Moore, C. U. (1921). Arch. Pediat., 38, 672.

${ }^{29}$ Williams, T. H., and Boyd, W. (1926). Surg. Gynec. Obstet., 42, 57.

${ }^{s 0}$ Raestrup (1928). Dtsch. Zi. ges. gerichtl. Med., 11, 373. 
${ }^{31}$ Murdoch, J. R. (1928). Lancet, 2, 1292.

3: Smead, L. F. (1931). Amer. J. Surg., 13, 497.

${ }^{3} 3$ Vinson, P. P. (1932). Arch. Otolaryng., Chicago, 16, 329

${ }^{34}$ Weiss, S., and Mallory, G. K. (1932). J. Amer. med. Ass., 98, 1353.

${ }^{35}$ Griffith, R. S. (1932). Pennsylvania med. J., 35, 639.

${ }^{36}$ Popper, H. L. (1933). Med. Klinik, 29, 810.

${ }^{37}$ Gott, R., Jr. (1933). Amer. J. med. Sci., 186, 400.

${ }^{38}$ Girard, J. (1934). Gaz. Hôp., 107, 1117.

${ }^{30}$ Mandler, (1934). Thèse Nancy (quoted by Terracol, 1938).

${ }^{40}$ Kyle, J. T. (1935). Brit. med. J., 1, 977.

${ }^{41}$ Guilmoto, G. E. (1936). Thèse Bordeaux (quoted by Terracol, 1938).

${ }^{42}$ Ridgeway, E. C., and Duncan, G. G. (1937). Bull. Ayer. Clin. Lab. Pennsylvania Hosp., 3, 79.

${ }^{43}$ Heyfelder (1938). Med. Anal., 4, 243.

${ }^{44}$ Heller, E. P. (1939). J. Mo. med. Ass., 36, 317.

45 Aldrich, C. A., and Anspach, W. E. (1939). Radiology, 32, 93.

${ }^{46}$ Mallam, P. C., Whitelock, H. A. B., and Robb-Smith, A. H. T. (1940). Brit. J. Surg., 27, 794.

4 ; Desjardins, E. (1940). J. Hôtel-Dieu Montréal, 9, 82.

${ }^{48}$ Charbonnel and Darmaillacq (1940). J. Méd. Bordeaux, 117, 212.

${ }^{49}$ Whipple, A. O., Nelson's Loose-Leaf Living Surgery, New York, 4, 130.

${ }^{50}$ Klein, L., and Grossman, M. (1943). Med. Bull. Vet. Adm. Wash., 19, 277.

${ }^{51}$ Collis, J. L., Humphreys, D. R., and Bond, W. H. (1944). Lancet, 2, 179.

\section{REFERENCES}

Ballin, M., and Saltzstein, H. C. (1922). Surg. Gynec. Obstet., 34, 42. Belsey, R. (1946). Thorax 1, 39.

Benson, C. D., and Penberthy, G. C. (1938). Surgery, 4, 777.

Cabot, H. (1936). Modern Urology, Lea and Febiger, Philadelphia, 2, 510.

Glass, W. E., and Freeman, W. (1935). Amer. J. med. Sci., 189, 80 .

Mackenzie, M. (1884). Diseases of the Nose and Throat, 2, 160. Churchill ; London.

Mallory, T. B. (1940). New Engl. J. Med., 222, 230.

Michel (de Nancy) (1880). Dictionnaire Encyclopédique des Sciences méd. Paris, article "Oesophage," 66, 436. Masson.

Phillips, C. E. (1938). J. Amer. med. Ass., 111, 998.

Rhode, C., in Handbuch der Hals-Nasen-Ohron-Heï!kunde, Denker A. et Kalher, O. Band., 9, 413. Springer, Berlin.

Starling, E. H. (1920). Principles of Human Physiology, 3rd Ed., Churchill, London, 746.

Terracol, J., et al. (1938). Les Maladies de l'Oesophage, Masson et Cie., Paris, 360.

Vinson, P. (1921). Collected Papers of the Mayo Clinic, 13, 6.

Wagner, W. (1939). Arch. klin. Chir., 195, 161. 